\title{
ANÁLISE DE ADULTERANTES NO LEITE DE VACA IN NATURA COMERCIALIZADO INFORMALMENTE NO INTERIOR DO ESTADO DO CEARÁ
}

\author{
Ana Emília Formiga Marques ${ }^{1}$, Felisberto Farias Santos ${ }^{2}$, Flávia Duarte Alves ${ }^{3}$, \\ Elijadson Pereira Silva ${ }^{2}$, Daniel José De Oliveira Filho ${ }^{2}$, Cristina De Santana \\ Farias $^{2}$ \\ ${ }^{1}$ Profa ${ }^{\mathrm{a}}$ Unidade Acadêmica de Saúde, Faculdade de Medicina Estácio de Juazeiro do Norte, \\ Juazeiro do Norte, CE, Brasil. \\ ${ }^{2}$ Curso de Bacharelado em Farmácia, Unidade Acadêmica de Saúde, Faculdade de Medicina \\ Estácio de Juazeiro do Norte, Juazeiro do Norte, CE, Brasil. \\ ${ }^{3}$ Curso de Bacharelado em Fisioterapia, Unidade Acadêmica de Saúde, Faculdade de \\ Medicina Estácio de Juazeiro do Norte, Juazeiro do Norte, CE, Brasil.
}

\begin{abstract}
Resumo
O leite é um dos principais alimentos consumidos no mundo, devido suas características organolépticas e nutricionais. Sua falta de qualidade no mercado informal está relacionada a diversas formas de fraudes, causando diversos problemas alimentares e de saúde coletiva. Essa pesquisa teve como objetivo analisar adulterantes no leite de vaca in natura comercializado informalmente no interior do estado do Ceará. Sendo de caráter analítico descritivo. Foram analisadas 20 amostras de leite, realizando testes de acidez de Dornic, determinação do pH e características organolépticas, adulteração por peróxido de hidrogênio e solução alizarina; presença de cloretos, sacarose, bicarbonato de potássio e amido. Nas analises, 95\% apresentaram irregularidades em pelo menos um dos quesitos comparados e analisados frente aos padrões estipulados pelos órgãos reguladores como o MAPA. Delas, 35\% apresentaram o $\mathrm{pH}$ alterado, $10 \%$ adição de soda caustica, $85 \%$ de bicarbonato de potássio, $15 \%$ de sacarose e $20 \%$ alteração nas características organolépticas. Em 100\% das amostras não houve adição de peróxido de hidrogênio, cloreto e amido. Os resultados do trabalho evidenciaram o perigo que 0 consumidor do leite cru informal está exposto devido a presença de adulterantes, possível adição de água e falta de higiene no manejo, falta de refrigeração adequada e prejuízo econômico.
\end{abstract}

Palavras-Chave: Controle de Qualidade. Fraude. Leite.

\begin{abstract}
Milk it's one of the most consumed food in the world considering organoleptic characteristics and nutritional facts, the poor quality of the raw milk selling in informal market was been related with many fraud activities causing alimentary and serious health problems. The purpose of this study was determined the presence of fraudulent substances in the raw milk in selling in inner cities in the state interior of Ceará. This study is a descriptive analytical. 20 samples were evaluated tested dornic tritatable, $\mathrm{pH}$ determination and alizarin solution also organoleptic characteristics, sodium hydroxide adulteration It was used specific methods for detection of restoratives: chlorine, sucralose, bicarbonate and starch. according with the sample analyses it was found irregularity in $95 \%$ in the milk in at least one fraud test with standard stipulated by regulation organs. Among them $35 \%$ present altered $\mathrm{pH}$, in $10 \%$ of the samples was detected sodium hydroxide addition, $85 \%$ of bicarbonate and $15 \%$ of sucralose. For organoleptic characteristic $20 \%$ presents alteration. There's was not positives results to hydrogen peroxide addition. Chlorine and Starch. The results presented in this study demonstrated the danger that raw milk consumers are exposed most because adulterants presence besides financial losses that this type of fraud may cause as the possible lack of hygiene in the dandling, lack of adequate refrigeration and the probable addition of water.
\end{abstract}


Key words: Quality Control. Fraud. Milk.

\section{Introdução}

Leite é denominado como o produto fresco e integral oriundo da ordenha ininterrupta e completa de vacas sadias. Possui como atributos físico-químicos glóbulos gordurosos que se mantem em suspensão caracterizando como uma emulsão de cor branca, ligeiramente amarelada, de gosto adocicado e odor suave que contém substancias nutritivas. Possui na sua composição química água $(87 \%)$, carboidratos $(4,9 \%)$, proteínas $(3,5 \%)$, minerais $(0,7 \%)$, além de vitaminas que podem apresentar variações resultante da alimentação, raça, época do ano e dentre outros fatores (HOCHMÜLLER et al., 2017; BISOGNIN et al., 2016; WESCHENFELDER et al., 2016).

Estima-se que a produção de leite deverá passar de um volume de 37,2 bilhões de litros para valores entre 47,5 e 52,7 bilhões ao final de 2025 . Entretanto, um fator relevante que impede o Brasil de atingir mercados mais exigentes é a qualidade questionável do produto lácteo devido as limitações tecnológicas relacionadas à falta de estabilidade térmica, limitações que dificultam a melhoria da qualidade de produtos lácteos e o aumento da vida de prateleira. A falta de qualidade do leite no mercado informal está relacionada a diversas formas de fraudes, que tem como finalidade a de mascarar a má qualidade do mesmo, embora já se tenha conhecimento que tal procedimento possa causar diversos problemas alimentares e de saúde coletiva somados a prejuízos econômicos (SANTOS et al., 2018; SILVA; OLIVEIRA, 2017; BRASIL, 2015).

A fraude envolvendo alimentos pode ser caracterizado como um ato intencional de incluir diluição; substituição de componentes; manipulação do produto; falsa rotulagem/apresentação ou falsas alegações sobre o produto. Os atos fraudulentos não tem inicialmente a intenção de causar danos na saúde pública, entretanto podem ocasionar implicações negativas causando doenças e comprometendo a saúde dos consumidores, podendo levar até mesmo a morte (GFSI, 2014).

Neste enquadre situacional, características sensoriais e físico-químicas, tais como odor e sabor são avaliados como parte de alguns testes que são 
empregados em vários países do mundo afim de avaliar a qualidade do leite fluido, em razão da sua rica composição em macronutrientes somado ao fato de possuir um $\mathrm{PH}$ próximo da neutralidade. O leite bovino constitui um meio mais que adequado para a multiplicação e desenvolvimento de vários microrganismos, fazendo-se necessário obter mais parâmetros para assegurar a qualidade do produto lácteo como contagem bacteriana total (CBT), contagem de células somáticas (CCS), ausência de microrganismos patogênicos, ausência de conservantes químicos, resíduos microbianos, pesticidas ou outros produtos considerados nocivos para seres humanos. Para os produtores, a indústria e os consumidores, as características do leite são valiosas, enfatizando a grande importância na produção e prática de consumo de derivados. Assim sendo, é primordial compreender alguns conceitos a respeito da qualidade do leite se tratando principalmente das condições higiênico-sanitárias (JAMAS, et al., 2017; SOUZA, 2016; TONINI, 2014).

Não obstante a legislação dispões de critérios mínimos de qualidade, constata-se no Brasil, nos últimos anos inúmeros casos de adulteração de alimentos, em especial concernentes a cadeia produtiva do leite, compreendendo indústria de grande porte e produtores, evidenciando vulnerabilidades no sistema de produção do leite em larga escala e questionamentos se as ferramentas de controle de qualidade e sistemas de inspeção estão sendo hábeis para assegurar a segurança dos alimentos produzidos. É importante salientar, que ainda é comum no Brasil e em vários lugares do mundo a pratica da comercialização clandestina do leite cru não pasteurizado, transportado em bicicletas, motos e caminhões, armazenados sem refrigeração e controle higiênico-sanitário, sobretudo em cidades do interior (CRUZ; SCHNEIDER, 2010).

Neste contexto, o objetivo da pesquisa foi analisar se o leite cru não pasteurizado comercializado em algumas cidades do interior do estado do Ceará apresenta desvio de qualidade em relação a adição de conservantes ou outros adulterantes.

Nesta perspectiva, nossa pergunta norteadora de pesquisa, assim se delineia: o leite cru não pasteurizado vendido no comércio informal aos 
consumidores de algumas cidades no interior do Estado do Ceará sofreram algum tipo de adulteração e/ou atendem aos critérios mínimos de qualidade?

\section{$2 \quad$ Metodolodia}

\subsection{Tipos de Estudo}

Este estudo é um experimental de caráter analítico descritivo quantiqualitativo.

\subsection{Local do Estudo}

As análises laboratoriais necessárias para execução deste trabalho foram realizadas no Laboratório de Tecnologia de Alimentos da Faculdade de Medicina Estácio de Juazeiro do Norte.

\subsection{Coleta das Amostras}

As amostras de leite utilizados neste estudo foram adquiridas no primeiro semestre de 2019 em algumas cidades do interior do estado do Ceará (Juazeiro do Norte, Barbalha, Várzea Alegre, Jardim e Granjeiro), foram coletadas através do recipiente original disponibilizado pelo vendedor (garrafas pet e sacos plásticos), em seguida armazenadas em recipiente isotérmico com gelo e levadas até o laboratório de Tecnologia de Alimentos da Faculdade de Medicina Estácio Juazeiro do Norte, onde foram realizados as determinações analíticas afim de detectar a presença de adulterantes nas amostras.

Foram obtidas 20 amostras de leite originadas das cidades citadas acima, os vendedores possuíam comércio em mercados, barracas em calçadas, vendedores em carros e motos e qualquer outro tipo de comércio que se configure informal, que não haja nenhum tipo de rastreabilidade do produto. As amostras foram adquiridas no ao longo do mês de maio do ano de 2019.

\subsection{Testes realizados}

Todos os testes foram realizados baseados nas metodologias preconizadas pelo o Instituto Adolf Lutz (2008).

\subsubsection{Acidez Dornic}

Transferiu-se, com auxílio de uma pipeta volumétrica, $10 \mathrm{~mL}$ da amostra para um béquer de $100 \mathrm{~mL}$. Adicionou-se 5 gotas da solução de fenolftaleína a 
$1 \%$. Titulou-se com a solução de hidróxido de sódio N/9, utilizando bureta de 10 $\mathrm{mL}$ ou acidímetro de Dornic, até o aparecimento de uma coloração rósea. Após foi feito a leitura e dado o resultado em graus Dornic.

Nota: cada $0,1 \mathrm{~mL}$ da solução de hidróxido de sódio $\mathrm{N} / 9$ equivale a $1^{\circ} \mathrm{D}$.

\subsubsection{Determinação do pH}

Para a determinação do $\mathrm{pH}$ das formulações em estudos, foi medido por meio de um pHmetro previamente calibrado com as amostras na temperatura de $20^{\circ} \mathrm{C}$

\subsubsection{Determinação das características organolépticas}

Foram observadas nas amostras em estudo as seguintes características: aspecto, cor, odor, homogeneidade e separação de fases observado por apenas um analista afim de evitar viés observacional.

\subsubsection{Adulteração por peróxido de hidrogênio}

Para a detecção de conservantes do leite, inicialmente verificou se haveria presença do peróxido de hidrogênio $\left(\mathrm{H}_{2} \mathrm{O}_{2}\right)$ nas amostras, para o teste foram necessários tubos de ensaio no qual foram colocados $2,0 \mathrm{~mL}$ de leite e algumas gotas de iodeto de potássio a $10 \%$. O resultado positivo foi diagnosticado pela mudança de coloração apresentando uma cor mostarda.

\subsubsection{Teste solução de alizarina}

Para a verificação da presença de soda cáustica no leite, foram colocados nos tubos de ensaio $2,0 \mathrm{~mL}$ da amostra e algumas gotas de solução de alizarina a $2 \%$. A cor violeta indicou resultou-se positivo e rósea-tijolo negativo.

\subsubsection{Presença de cloretos}

A avaliação da presença dos reconstituintes no leite foi realizada para cloretos (sal), adicionando-se $2,0 \mathrm{~mL}$ de leite, dois $\mathrm{mL}$ de cromato potássico a $5 \%$ e $2,0 \mathrm{~mL}$ de nitrato de prata a $10 \%$ em tubos de ensaio. Na leitura do teste, a cor tijolo apresentou resultado negativo e a cor amarelo-ovo, positivo. 


\subsubsection{Detecção da presença de sacarose}

Para a detecção da sacarose (açucares), colocaram-se no tubo de ensaio 2,0 mL de leite e 0,5 mL de ácido clorídrico P.A, incubou-se em banho-maria fervente por um minuto. A leitura foi realizada quando a amostra atingiu a temperatura ambiente, sendo positiva a que ficasse com a cor caramelo.

\subsubsection{Presença de bicarbonato de potássio}

Para a avaliação da presença de bicarbonato de potássio, inicialmente foram retirados $5 \mathrm{~mL}$ de cada amostra de leite e adicionados de 5 a 6 gotas de nitrato de prata a $2 \%$, em seguida as amostras foram aquecidas em banho maria por 30 minutos e o resultado foi observado na mudança de coloração, sendo a cor vermelho-tijolo positivo e para um resultado negativo a cor permanecia inalterada.

\subsubsection{Presença de amido}

Para avaliação da presença de amido, foram submetidos à fervura 5,0 mL de cada amostra de leite, sendo em seguida resfriados e então adicionadas duas gotas de lugol. interpretação do teste, azul indicava leite fraudado com amido e a cor amarela, negativo.

\subsection{Análises dos dados}

Os dados do estudo foram lançados e organizados no Microsoft Office Excel, através de estatística descritiva.

\section{Resultados e discussão}

As amostras foram adquiridas em algumas cidades do interior do estado do Ceará, provenientes de vendedores informais e em seguida foram analisadas obedecendo aos métodos analíticos oficiais recomendados pelo Ministério da Agricultura e de acordo com o Regulamento Técnico de Identidade e Qualidade do Leite Cru Refrigerado da Instrução Normativa 68 (BRASIL, 2006). Nas vinte amostras analisadas, algumas continham conservantes ou adulterantes, geralmente utilizadas na fraude do leite. Quanto às características principais do leite os resultados são apresentados na tabela 1 a seguir: 
Tabela 1. Características físico-químicas do leite de vaca in natura comercializado informalmente no interior do estado do Ceará

\begin{tabular}{|c|c|c|c|c|}
\hline Amostras & $\mathrm{pH}^{*}$ & $\begin{array}{l}\text { Características } \\
\text { Organolépticas }^{*}\end{array}$ & $\begin{array}{l}\text { Acidez }^{\star \star \star} \\
\left(15-20^{\circ}\right)\end{array}$ & \\
\hline 01 & 6,76 & Característico & $15^{\circ} \mathrm{D}$ & Conforme \\
\hline 02 & 4,49 & Característico & $15^{\circ} \mathrm{D}$ & Conforme \\
\hline 03 & 6,91 & Característico & $16^{\circ} \mathrm{D}$ & Conforme \\
\hline 04 & 6,79 & Característico & $20^{\circ} \mathrm{D}$ & Conforme \\
\hline 05 & 6,79 & Característico & $15^{\circ} \mathrm{D}$ & Conforme \\
\hline 06 & 6,52 & Esbranquiçado & $10^{\circ} \mathrm{D}$ & Ácido \\
\hline 07 & 6,76 & Característico & $14^{\circ} \mathrm{D}$ & Ácido \\
\hline 08 & 6,73 & Característico & $20^{\circ} \mathrm{D}$ & Conforme \\
\hline 09 & 6,76 & Característico & $14^{\circ} \mathrm{D}$ & Ácido \\
\hline 10 & 6,75 & Característico & $20^{\circ} \mathrm{D}$ & Conforme \\
\hline 11 & 6,93 & Característico & $19^{\circ} \mathrm{D}$ & Conforme \\
\hline 12 & 6,76 & Característico & $10^{\circ} \mathrm{D}$ & Ácido \\
\hline 13 & 6,79 & Amarelado & $10^{\circ} \mathrm{D}$ & Ácido \\
\hline 14 & 7,90 & Característico & $10^{\circ} \mathrm{D}$ & Ácido \\
\hline 15 & 6,91 & Característico & $10^{\circ} \mathrm{D}$ & Ácido \\
\hline 16 & 6,58 & Característico & $20^{\circ} \mathrm{D}$ & Conforme \\
\hline 17 & 6,32 & Esbranquiçado & $20^{\circ} \mathrm{D}$ & Conforme \\
\hline 18 & 6,48 & Amarelado & $19^{\circ} \mathrm{D}$ & Conforme \\
\hline 19 & 6,58 & Característico & $20^{\circ} \mathrm{D}$ & Conforme \\
\hline 20 & 6,91 & Característico & $20^{\circ} \mathrm{D}$ & Conforme \\
\hline \multicolumn{5}{|c|}{${ }^{*} 20^{\circ} \mathrm{C}$} \\
\hline
\end{tabular}


As amostras foram analisadas e colocadas na tabela $1 \mathrm{em}$ ordem de recebimento, se dispondo da seguinte maneira: Jardim (01 e 02), Barbalha $(03,09,11,12,13,14,15,17)$, Juazeiro do Norte $(04,05,06,07,08)$, Crato $(10)$, Várzea Alegre $(16,18,19)$ e Granjeiro $(20)$.

Do total de 20 amostras, 19 (95\%) foram reprovadas pela detecção de substâncias fraudulentas. No entanto, considerando os valores próximos a neutralidade que naturalmente está entre 6,6 e 6,8. (35\%) das amostras estariam fora dos padrões. De acordo com dados da tabela 1, os valores de $\mathrm{pH}$ para as amostras $(01,04,05,06,07,08,09,10,12,13,16,18$ e 19) estão dentro da faixa ideal. As amostras que ficaram abaixo dos valores de normalidades foram (02 e 17), e acima as $(03,11,14,15$ e 20$)$. Nos casos graves de mastite, o $\mathrm{pH}$ pode chegar a mais de 7,5 o que pode ter sido o caso da amostra 14 e na presença de colostro, pode cair para 6,0. Esta acidez, é denominada de acidez natural do leite e varia entre 0,13 e 0,17 por cento e expressado como o ácido lático, por características de sua própria constituição, ou seja, devido a presença de dióxido de carbono, citratos, albumina fosfato e caseína; entretanto condições higiênico-sanitárias deficientes ou até mesmo $\mathrm{o}$ armazenamento inadequado a refrigeração inadequada podem levar ao aumento da proliferação bacteriana, consequentemente as enzimas produzidas por essas bactérias mesófilas degradam a lactose formando mais ácido lático e compostos secundários resultando na acidez adquirida do leite. Logo a acidez real do leite é a combinação da acidez adquirida e da acidez natural (ZEQUI, 2013).

De acordo com o trabalho realizado por Silva e Oliveira (2017) os resultados dos valores encontrados no seu estudo para acidez foram de 37,5\% muito próximos ao resultado encontrado nessa pesquisa que foi de $35 \%$, ambas apresentando resultados fora da legislação em vigor.

Em relação as características organolépticas, as amostras (06 e 17) apresentaram-se esbranquiçada e as (13 e 18) mostraram-se amareladas, diferentes do usual. A cor branco-opaca pode estar relacionada principalmente à dispersão da luz pelas micelas de caseína, glóbulos de gordura dispersam a luz, mas pouco contribuem para a cor branca do leite. A cor amarelada das 
amostras 13 e 18 podem estar relacionadas a substancias lipossolúveis como caroteno e a riboflavina (VENTURINI; SARCINELLI; SILVA, 2007).

Em relação à acidez titulável, as amostras $(01,02,03,04,05,08,10,11$, 16, 17, 18, 19 e 20) (65 \%) apresentaram-se dentro de padrões, já as $(06,07,12,13,14$ e 15) (35\%) apresentaram valores inferiores. Este método tem por objetivo quantificar o teor de compostos ácidos presentes no leite, uma titulação ácida pode ser influenciada por vários fatores: pela própria composição do leite fresco, atividade enzimática, estágio da lactação e mastite por exemplo. Considera-se o resultado da análise como sendo um indicador das condições de higiene e refrigeração do leite.

De acordo com o estudo de Fernandes e Maricato (2010) demonstraram um percentual inferior para acidez titulável nesse estudo os pesquisadores avaliaram o leite recebido em laticínios na cidade de Bicas em Minas Gerais, do total de amostras de leite cru analisadas 100\%, ou seja, 50 amostras analisadas estavam dentro do parâmetro estabelecidos pela legislação.

Nos estudos de Silva et al, (2017) no qual os pesquisadores identificaram 6 pontos referentes aos comerciantes que atendem ao maior número de famílias, considerados os maiores vendedores em volume de leite/dia resultando num total de $37 \%$ das amostras fora dos parâmetros de normalidade para acidez titulável.

Já nos estudos de Silveira e Bertagnolli (2014), que teve como objetivo avaliar a qualidade do leite cru comercializado informalmente em feiras livres no município de Santa Maria, RS, no qual às amostras de leite in natura foram adquiridas diretamente dos feirantes em feiras livres. Dez amostras de leite cru informal foram analisadas, mas apenas duas não apresentaram alterações em relação à acidez titulável.

Relacionado a pesquisa de fraude no leite, foram realizados alguns testes visando identificar a presença de conservantes e/ou substâncias químicas adicionadas ao leite. Os dados obtidos estão dispostos na tabela 2: 
Tabela 2. Testes para adulterantes no leite de vaca in natura comercializado informalmente no interior do estado do Ceará.

\begin{tabular}{ccccccc}
\hline Amostras & $\begin{array}{c}\text { Peróxido } \\
\text { de } \\
\text { Hidrogênio }\end{array}$ & $\begin{array}{c}\text { Soda } \\
\text { caustica }\end{array}$ & Cloretos & Sacarose & $\begin{array}{c}\text { Bicarbonato } \\
\text { de Potássio }\end{array}$ & Amido \\
\hline 01 & - & - & - & - & + & - \\
\hline 02 & - & - & - & - & + & - \\
\hline 03 & - & - & - & - & + & - \\
\hline 04 & - & - & - & - & + & - \\
\hline 05 & - & - & - & - & - & - \\
\hline 06 & - & - & - & - & - & - \\
\hline 07 & - & - & - & - & + & - \\
\hline 08 & - & - & - & - & + & - \\
\hline 09 & - & - & - & - & + & - \\
\hline 10 & - & - & - & - & + & - \\
\hline 11 & - & - & - & - & + & - \\
\hline 12 & - & - & - & - & + & - \\
\hline 13 & - & - & - & - & - & - \\
\hline 14 & - & - & - & - & + & - \\
\hline 15 & - & - & - & - & + & - \\
\hline 16 & - & + & - & - & + & - \\
\hline 17 & - & - & - & + & + & - \\
\hline 18 & - & - & - & + & + & - \\
\hline 19 & - & - & - & - & + & - \\
\hline 20 & - & + & - & + & + & - \\
\hline
\end{tabular}

*Peróxido de hidrogênio

** Hidróxido de Sódio

$\mathrm{Na}$ pesquisa de fraude nenhuma das amostras apresentaram positivo para adição de peróxido de hidrogênio, cloreto e amido, semelhantes ao trabalho de Rocha, Oliveira e Carvalho (2016), na qual, todas as amostras avaliadas apresentaram resultado negativo. No teste de detecção de soda caustica $10 \%$ das amostras foram identificadas como positivas (16 e 20) dentre as 20 analisadas, onde apresentaram a coloração violeta.

Já no resultado do teste para presença de bicarbonato de potássio foi negativo nas amostras (05, 03 e 13), onde a coloração permaneceu inalterada; nas demais, $85 \%$ das amostras, foram encontradas mudanças na coloração obtendo a cor vermelho-tijolo, resultando-se positivo. Dos neutralizantes, o bicarbonato é facilmente obtido e utilizado para disfarçar o estado de 
deterioração do leite e essa adição de bicarbonatos constitui fraude. Sua presença pode ser detectada facilmente pela coloração vermelho-tijolo (SCHNEIDER, 2016).

A detecção de açucares (sacarose), foi encontrado em 15\% das amostras $(17,18$ e 20). A fraude do leite com sacarose não altera o sabor, é uma das mais comuns e não causa nenhum dano à saúde do consumidor. Entretanto, ocasiona a redução do valor nutricional além de mascarar uma possível adição de água (MAREZE et al., 2015).

Segundo Abrantes, Campêlo e Silva (2014) a adição de água no leite ainda continua sendo a principal fraude detectada, tendo como objetivo aumentar o seu volume. Essa adição reduz o seu valor nutritivo, procedimento este que além de prejudicar a qualidade microbiológica do produto, reflete a falta de comprometimento com a qualidade e produção do leite.

No estudo de Montanhini e Hein (2013), no qual foi analisado a qualidade do leite comercializado informalmente, resultando nenhuma das amostras de leite comercializado informalmente estava de acordo com os padrões estabelecidos pela Instrução Normativa № 62 . Diferente dos dados encontrados por Catanio et al. (2012), que encontraram todas as amostras de leite in natura dentro dos padrões físico-químicos estabelecidos pela legislação. Essas amostras eram provenientes de produtores que entregam o leite em um laticínio na Região Norte do Paraná. Isto demonstra que o produtor que entrega o leite diretamente para indústria evita a adulteração, pois sabe que o produto irá passar pelo controle de qualidade ao ser recebido na usina.

No estudo de Mendes e colaboradores (2010), teve como objetivo analisar a qualidade do leite informal comercializado no município de Mossoró, Rio Grande do Norte. Foi realizado em comum com nosso estudo a pesquisa de fraudes, no qual foram analisados acidez em graus Doric, adição de água, de conservantes como soda caustica, bicarbonato de potássio e reconstituintes como sacarose, amido e cloreto. Das análises de fraudes realizadas, a única observada no leite foi a adição de água, a maioria apresentando irregularidades estando imprópria para a comercialização. 


\section{Conclusões}

A avaliação da qualidade do leite informal comercializado em algumas cidades do interior do estado do Ceará através de análises da pesquisa de fraude, permitiu constatar que $95 \%$ das amostras apresentaram irregularidades em pelo menos um dos quesitos comparados e analisados frente aos padrões estipulados pelos órgãos reguladores.

Os resultados do presente trabalho evidenciaram o perigo no qual 0 consumidor do leite cru informal está exposto, devido a presença de adulterantes, além do prejuízo financeiro que essas fraudes proporcionam ao consumidor final. A possível falta de higiene no manejo, a falta de refrigeração adequada e a provável adição de água foram os principais problemas observados. No entanto, os resultados das análises fora do padrão de normalidade para cada amostra não devem ser avaliados individualmente, mas como um conjunto, pois a alteração de um parâmetro não necessariamente corresponde a uma fraude, visto que os componentes do leite possuem uma variação natural devido a aspectos fisiológicos e nutricionais de cada animal.

É muito importante que a população que consome este tipo de leite seja orientada, pois este apresenta a sua qualidade reduzida, o que foi conferido nos resultados das análises. Tendo em vista que tenham a possibilidade de adquirirem doenças desencadeadas pela adição desses adulterantes.

\section{Referências}

ABRANTES, M.R; CAMPÊLO, C.S; SILVA, J.B.A. Fraude em leite: Métodos de detecção e implicações para consumidor. Revista do Instituto Adolfo Lutz, v.73, n.3, p.244-251, 2014.

BISOGNIN, F; SALAZAR, L.N; MATTOS, G.S; BOFF, V.A; SALAZAR, R.F.D.S. Caracterização físico-química do leite para produção de derivados lácteos em um laticínio na região noroeste do Rio Grande do Sul nota técnica. Revista SODEBRAS v.11, n.131, 2016.

BRASIL. Ministério da Agricultura, Pecuária e Abastecimento. Assessoria de Gestão Estratégica. Projeções do Agronegócio, Brasil 2014/15 a 
2024/25. Brasília 2015 Disponível em: <http://www.agricultura.gov.br>. Acessado em: 11 agosto de 2018.

BRASIL. Ministério da Agricultura, Pecuária e Abastecimento. Instrução Normativa $n^{\circ}$ 68, de 12 de dezembro de 2006. Oficializa os Métodos Analíticos Oficiais Físico-Químicos, para Controle de Leite e Produtos Lácteos, em conformidade com o anexo desta Instrução Normativa, determinando que sejam utilizados nos Laboratórios Nacionais Agropecuários. Diário Oficial da União, Brasília, 2006.

BRASIL. Ministério da Agricultura, Pecuária e Abastecimento. Instrução Normativa no. 051, de 18 de setembro de 2002. Diário Oficial da União, Brasília, 20 set., Seção 1, p.13-22. 2002.

CATANIO, F.S. et al. Refrigerated raw milk quality of processing plant in the north of Paraná after the implementation of changes imposed by NI62 of 2011. Semina: Ciências Agrárias, v.33, n.2, p.3171-3180, 2012.

CRUZ, F. T., SCHNEIDER, S. Qualidade dos alimentos, escalas de produção e valorização de produtos tradicionais. Revista Brasileira de Agroecologia, v.5, n.2, 2010.

FERNANDES, V.G; MARICATO, E. Análises físico-químicas de amostras de leite cru de um laticínio em BICAS-MG. Revista do Instituto de Laticínios Cândido Tostes, v. 65, n. 375, p. 3-10, 2010.

Global Food Safety Initiative. "GFSI Position on Mitigating the Public Health Risk of Food Fraud." Global Food Safety Initiative, Consumer Goods Forum, 2014.

INSTITUTO ADOLFO LUTZ. Normas Analíticas do Instituto Adolfo Lutz. v. 1: Métodos químicos e físicos para análise de alimentos, 3.ed. São Paulo: IMESP, p.214, 1985.

HOCHMÜLLER, A.L.H; HOCHMÜLLER, J.H; CERESER, N.D.S; SALAZAR, R.F; SALAZAR, L.N. Estudo exploratório em leites UHT para verificação de 
ocorrência de adulteração. Revista interdisciplinar de ensino, pesquisa e extensão. v.4, n.1, 2017.

JAMAS, L.T; ROSSI, R; SALINA, A; MENOZZI, B.D; LANGONI, H. Agricultura familiar e parâmetros da qualidade do leite bovino no município de Bofete, estado de São Paulo, Brasil. Revista de Educação Continuada em Medicina Veterinária e Zootecnia do CRMV-SP. v.14, n.3, p.88-88, 2017.

MAREZE, J; MARIOTO, L.R.M; GONZAGA, N; DANIEL, G.C; TAMANINI, R; BELOTI, V. Detecção de adulterações do leite pasteurizado por meio de provas oficiais. Semina: Ciências Biológicas e da Saúde, v.36, n.1, p.283-290, 2015.

MENDES, C.G; SAKAMOTO, S.M; SILVA, J.B.A; JACOMÉ, C.G.M; LEITE, A.I. Análises físico-químicas e pesquisa de fraude no leite informal comercializado no município de Mossoró, RN. Ciência Animal Brasileira, v.11, n.2, p.349-356, 2010.

MONTANHINI, M.T.M; HEIN, K.K. Qualidade do leite cru comercializado informalmente no município de Piraí do Sul, Estado do Paraná, Brasil. Revista do Instituto de Laticínios Cândido Tostes, v.68, n.393, p.10-14, 2013. ROCHA, K. OLIVEIRA L; A.P; CARVALHO, J.P. Avaliação da qualidade do leite "in natura", pasteurizado e esterilizado (uht), comercializado em Barra do Bugres-MT. Enciclopédia Biosfera, v.13, n.23, p.114-126, 2016.

SANTOS, M.C.M; CERQUEIRA, M.M.O.P; LEITE, M.O; SOUZA, M.R. Desenvolvimento de um modelo preditivo para identificação de perda de estabilidade e ocorrência de proteólise em leite UAT. Arquivo Brasileiro de Medicina Veterinária e Zootecnia. v.70, n.1, p.247-253, 2018.

SILVA, G.W.N; OLIVEIRA, M.P; LEITE, K.D; OLIVEIRA, M.S; SOUSA, B.A.A. Avaliação físico-química de leite in natura comercializado informalmente no sertão paraibano. Revista Principia - Divulgação Científica e Tecnológica do IFPB, n.35, p.34-41, 2017. 
SILVEIRA, M.L.R; BERTAGNOLLI, S.M.M. Avaliação da qualidade do leite cru comercializado informalmente em feiras livres no município de Santa Maria-RS, Revista Visa em Debate, v.2, n.2, 2014.

SCHNEIDER, A.M. Trabalho de conclusão de curso atividades do estágio supervisionado obrigatório: Controle de qualidade e inspeção de produtos de origem animal, 2016.

SOUZA, A.R; DE LIMA, F.W.F; SILVA, G.A; PRADO, R.S. Análise microbiológica de leite cru refrigerado e industrializado proveniente de propriedades dos municípios de Carmo do Rio Verde, Itapaci, Ipiranga de Goiás, Nova América, Rubiataba e São Patrício-Goiás. REFACER-Revista Eletrônica da Faculdade de Ceres, v.5, n.1, 2016.

TONINI, C.B. Avaliação da qualidade do leite e caracterização de laticínios do estado do Espírito Santo. 2014. Dissertação de Mestrado.

VENTURINI, K.S.; SARCINELLI, M.F; SILVA, L.C. Características do leite. Vitória: UFES/Pró-Reitoria de Extensão, p.6, 2007. WESCHENFELDER, S; PAIM, M.P; GERHARDT, C.A.R.I.N.; WIEST, J.M. Avaliação da rotulagem nutricional e das características físico-químicas e microbiológicas de diferentes marcas de leite pasteurizado e leite UHT. Boletim de Indústria Animal. p.73-1, 2016.

ZEQUI, P.V. Controle da qualidade do leite recebido no laticínio Guaíra. 2013 